\title{
New Methodology for Evaluation and Project Management in Engineering
}

\author{
Daniela Vysloužilová, Karel Sellner
}

Faculty of Production Technology and Management, J. E. Purkyne University in Usti nad Labem. Pasteurova 3334/7, 400 01 Usti nad Labem. Czech Republic.E-mail: vyslouzilova@fvtm.ujep.cz, sellner@fvtm.ujep.cz

The goal of the proposed methodology is to manage and evaluate investments across the portfolio of projects in the company, with extra focus on selecting engineering projects into the portfolio. In order to design an objective methodology, several analyses were conducted to verify a general validity of the methodology. The starting point is using methods which allow a high degree of flexibility in solving problems. The ANP method is suitable for the determination of priorities in network systems with different types of dependencies between the elements of the system. The DEMATEL method is used in this methodology to formulate the structure of relationships between the criteria of the system and obtain the criteria importance in the system. All calculations were carried out using the MAXIMA and Super Decisions software. The proposed methodology has been verified on a case study using real-life data supplied by the participating company. There were used methods of decision making, especially methods of operations research, linear programming and team expert selection methods.

Keywords: ANP method, DEMATEL method, Operations research, Project portfolio Management

\section{Introduction}

Companies manage many projects in in different level of development. More projects, we call portfolio. Portfolio projects (PP) is also a group of projects that are realized in the same organization. Unlike project management of only one project portfolio of projects have to do management at a higher hierarchical level. It is necessary to oversee the entire project portfolio, take into account the previous experience, on current projects, on organizational environment and future organizational plans (Engwall, 2003). For this reason, information exchange, resource management and coordination of project selection become even more important for the portfolio of projects rather than for an individual project.

Objective article is presentation of modern methodology of project portfolio selection corresponding with theoretical foundations of PPM. First chapter describes a method used in methodology. The next section intruduces single steps of summary metodology Selection of Projects in the portfolio. The status of work on the methodology and future outlooks are summarized in conclusion.

\section{Methods}

This chapter presents methods of operation research. The use of these methods in portfolio projects selection brings new possibilities. The selection was made according to their advantages and methodology requirements.

\subsection{The DEMATEL Method}

The DEMATEL method (the Decision Making Trial and Evaluation Laboratory) is an effective method to analyze relations (direct and indirect) between different parts of the system in relation to the type and severity). The DEMATEL method is applicable to the evaluation of many factors entering into portfolio assessment and to identify their relationships and evaluate their importance. (Altuntas \& Dereli, 2014) propose the use of a methodology for setting priorities in the portfolio of investment projects from the perspective of the government as the creator of incentives for investors. Solution procedure is based on knowledge of literature such as (Fiala, 2013).

The method proceeds from comparison scale to find influence and direction among system parts with respect to experts opinions. The comparison scale includes four levels of influence; no influence, low influence, medium influence and high influence. Paired evaluation of individual criteria carried out by each appointed experts. The resulting data entering the paired comparisons are given by the arithmetic average of all experts.

We are using the DEMATEL method for determination and quantification of direct and indirect links among projects in methodology. Simultaneously is method successfully applied to analyze criteria in the system. The result is the impact-relations-map. We can determine the importance of criteria from the map. The most important criteria are used like input data for the evaluation of the project within the portfolio.

\subsection{The ANP Method}

The ANP method (Analytic Network Process) network is a generalization of AHP (Analytic Hierarchy Process) method. The analytical network process (ANP) is a method that allows the system to include all possible interdependence and feedback. Structure of ANP model is described by clusters of elements and their interdependencies. Model ANP might reach several levels; the individual elements might be clusters of clusters of the next level etc. It is suitable for expressing dependencies within the network structures. Clusters model may represent variants, decision-makers, evaluation criteria and resources needed for implementation. Solving the model is described in (Saaty, 2008).

The relations among projects and criteria are created according to the results of DEMATEL methods. Other relations come out of company situation and its requirements. Responsible experts perform then pairwise comparisons. The advantage of using the method is, that company could on the fly as required change not only weights (priority) in evaluation but individual nodes of clusters 
(like e.g. criteria). We can add or take mutual relations according to the current situation in company or market environment.

\section{Performance of Methodology}

Based on the theoretical knowledge and on practical based consultations, we can propose evaluation methodology for investment projects in engineering companies. In its simplified form, it is possible to build a portfolio illustrated in Figure One.

In stage First screening, we are defining the general framework of the project. It includes below mentioned activities: collection of information about the project; determining the project costs; determining project revenues over the lifetime period; creating a project card; verification of compliance with the corporate strategy, identification variants of project; projects rough valuation; assessment of the projects necessity.

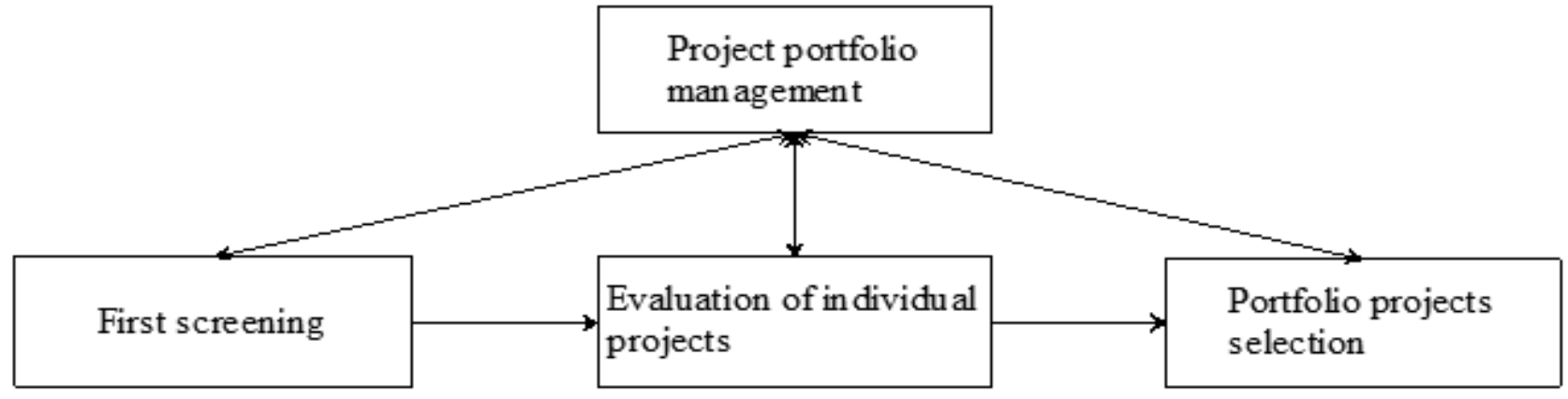

Fig. 1 Scheme to build a portfolio

Source: Own work, 2014

In phase Evaluation of individual projects, we are selecting suitable candidates to Portfolio. It comprises these activities: identification and analysis of risks; creating a risk register; effectiveness evaluation with help of financial criteria; adding a project card; assessment variants of project.

In Portfolio projects selection, we are deciding about the inclusion or non-inclusion of project into portfolio. We provides: criteria identification and determining their weight in the overall assessment; identification of the linkages and factor them in the assessment; projects selection in the portfolio according to sufficiency of resources; projects classification through portfolio.

All above mentioned phases come under the Project portfolio management. It secures besides others aftercare and management of project portfolio.

The methodology is introduced in detail in (Vysloužilová \& Fiala, 2015). The goal of our methodology is to choose the best projects into portfolio and to consider all source distribution among project to achieving excellent efficiency.

\section{Summary Methodology Selection of projects in the portfolio}

The portfolio projects selection includes a comparison between all the projects that have been evaluated as appropriate. The portfolio is selected based on the evaluation criteria and depending on the availability of resources. The portfolio projects selection comprises a combination of objective and subjective criteria. The metodology is summarized in Fig. 2.

It is possible take summary methodology apart into subsequent steps:

- 1 st Evaluation and selection of individual projects (so called candidate projects)

The projects which succesfully went through first screening are evaluate using standard methods in company.

- 2nd Formation and completion of the Projects Card

On the basis of documents is created Projects card, and gradually refilled.

- 3rd Candidate projects analysis by DEMATEL and identification of mutual relations

It is necessary to do pairwise comparisons among the projects entering in a project portfolio as a candidate using the following question: Does project A affects project $B$ ? The range of paired comparison is shown in Table 1 below. The result is information about mutual relations between projects.

Tab. 1 The range for paired comparisons using DEMATEL method

\begin{tabular}{|c|l|}
\hline Interval values & \multicolumn{1}{c|}{ The degree of influences } \\
\hline 0 & No effect \\
\hline 1 & Little impact \\
\hline 2 & Moderate impact \\
\hline 3 & Higher impact \\
\hline 4 & Very high impact \\
\hline
\end{tabular}

Source: Own work, 2014

The process of the DEMATEL method is based on the findings of the literature (Mehregan et al., 2012; Fiala, 2013) and can be defined in several steps: Creating the initial direct relationship matrix A; normalization of the initial direct relationship matrix $\mathrm{A}$; the calculation of the indirect influence matrix $\mathrm{T}$; determining the possible hierarchy or structure of elements and creating a map of relationships and impacts. It was created a source program for the DEMATEL method in a freely available MAXIMA program for calculation. The result is identification of all projects interrelations, which are afterwards used in following step. 


\section{- $\quad$ 4th Create Cluster Projects}

Based on the previous step, you can create a cluster of projects with identified interrelations. To calculate it in the SuperDecisions program, it is necessary to create the cluster in program under title Alternatives.

- 5th Analysis and selection of appropriate criteria
For the criteria analysis, it may be used the set of of criteria identified in the Table 2 . Identify appropriate criteria for the company and determine their importance using DEMATEL method. It could be used the program MAXIMA.

The pairwise comparisons among the criteria is done using the following questions: Does criterion A affect from your view criterion B? Scale pairwise comparison is shown in Table 1.

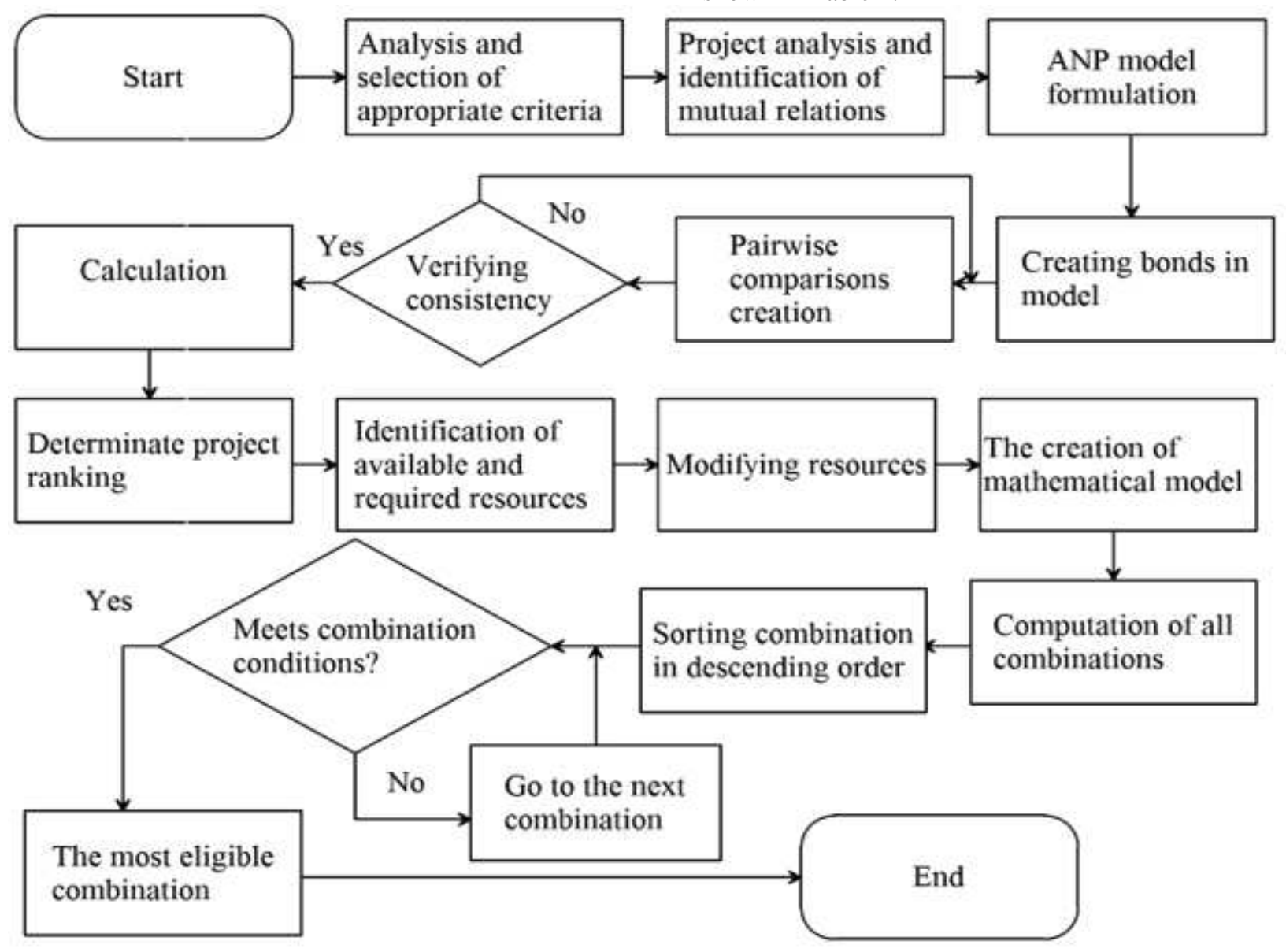

Source: Own work, 2017

Fig. 2 Flow chart Projects portfolio selection

Tab. 2 Set of criteria

\begin{tabular}{|l|l|l|}
\hline \multirow{5}{*}{ Financial criteria } & Net present value & K1 \\
& Labour costs saving & K2 \\
& Energy and material saving & K3 \\
& Possibility of grants & K4 \\
\hline \multirow{3}{*}{ Technical criteria } & Reducing of reject rate & K5 \\
& Device exploitability & K6 \\
& Requirements of assortment changes & K8 \\
\hline \multirow{2}{*}{ Economical criteria } & Increasing of producing capacity & K9 \\
\hline \multirow{3}{*}{ Social criteria } & Economic efficiency increasing & K10 \\
& Labour productivity increasing & K11 \\
\hline \multirow{3}{*}{ Project criteria } & Ecological criterion & K12 \\
& Social criterion & K13 \\
\hline & Working environment's improvement & K14 \\
& The probability of completing the project on time & K15 \\
& Type of project & K16 \\
\hline
\end{tabular}


Again, we used a source program for the DEMATEL method in a freely available MAXIMA program for calculation. The result is the identification of the interrelationships between the different criteria. These links are then used to determine the importance of individual criteria in company.

- 6th Create a cluster Criteria

The relevance of the criteria is determined with the help of DEMATEL method. In this case is used following question: Is criterion A more significant than criterion B? The range of paired comparison is shown in Table 1 above. Then use the same source program for the DEMATEL method like above. Create cluster Criteria from selected criteria with identified interrelations.

- $\quad 7$ th Create Cluster Resources

It is possible the recources divided in field energy, finance, hardware, infrastructure, material and grants. All needed sources are idetified on Project Card. It is necessary to consider their availability. From available resources is then created a cluster named Resources.

\section{- 8 th Creation Cluster Time}

Consider, how often you perform this analysis. It is recommended to perform these conversions in every important moment in time realized projects (eg. In different parts of the sub-project phases, in the event of discovery of a new project under consideration or in the case of a change on the available resources), but at least once per quarter of a year.

In the cluster Time are also included two elements entering in it: the life of the project and the duration of the realization. The cluster Time is created from available information.

- $\quad 9$ th Creating a model including reciprocal relationships within clusters and elements

Create a complete model including all links, between individual elements within the cluster, and beyond. The model might look like in Table 3.

This model will be after that including individual bonds transferred to the program SuperDecisions.

\section{Tab. 3 Nodes and clusters of ANP model in the proposed methodology}

\begin{tabular}{|l|l|}
\hline Criteria & Recources \\
\hline Financial & Energy \\
Econnical & Finance internal and external \\
Social & Humans \\
Project & Hardware and Infrastructure \\
& Material \\
\hline Time & Obtained grants \\
\hline Life of the project & Projects \\
Duration of realization & Project P1 \\
& Project P2 \\
& Project P3 \\
& Project P4 \\
\hline
\end{tabular}

Source: Own work, 2014

- 10 th The creation of the ANP model in program Super Decisions

Open the program SuperDecisions. Create all cluster. It is necessary to call one of them as Alternatives. In this case iunderthis cluster cluster with all projects. If you have all aluster, you can to each one make all nodes. After all clusters and all nodes have been created, you can assign linkages between clusters and indiviual nodes.

- 11 th Fill with pairwise comparison program SuperDecisions

All the bindings in the model have to be already defined to make the pairwise comparisons. After defining all the links, the program requires to complete all pairwise comparisons. The number of them is given by the number of bindings that were made.

- 12th Verification index inconsistencies in the program SuperDecisions

Inconsistency checking is performed directly in the program SuperDecisions. The value is automatically calculated after entering each pairwise comparison. Value inconsistency defines possible error in conclusions. Recommended value is below 0.1 . In case that the value is higher, it is desirable to adjust the pairwise comparison to meet the desired amount.

- 13th Model calculation and interpretation of results

The program after completing all necessary data calculates automatically. The ranking is based on the results of limit supermatrix.

- $\quad$ 14th Defining restrictive conditions, identifying resources and their reallocation

Based on the available knowledge and information on projects and their needs, you can identify the necessaryresources which are available in insufficient amount.

Sources, which available quantity does not cover the realization of all selected projects, come to the solution of this task as limiting conditions; on the contrary, the resources, which available quantity covers implementation of all selected projects, are neglected in the task. As maximization criterion we can used he ranking of projects. So, it could be created economical model. It is necessary to identify resources (inputs), results (outputs) and activities.

Using linear equations and inequations define proper 
task limitation.For example: On the right side, indicate the available quantity (the entry quantity limiting quantity or the required quantity of the exiting factor). On the left side, the amount of individual resources required is multiplied by individual projects.

- 15 th The definition of the task of the individual's proper limitations and convert them into a mathematical model

Using linear equations and inequations define proper task limitation.For example: On the right side, indicate the available quantity (the entry quantity limiting quantity or the required quantity of the exiting factor). On the left side, the amount of individual resources required is multiplied by individual projects. The order of projects in the form of weights enters the purpose-based function of the equation as the optimization criterion. This is maximization criterion. The sum of the weights of all projects is equal to 1 .

- 16th Calculation of possible combinations mathematical model

For the evaluation of projects, the solution is vector $\mathrm{x}_{\mathrm{i}}$ $=1,0$; where $\mathrm{i}=1, \ldots \mathrm{n}\left(\mathrm{x}_{\mathrm{i}}\right.$ defines whether or not the project will be implemented). The proposed calculation procedure uses the above mathematical model. Of $\mathrm{k}$ limitations and purpose function, are created the matrix $\mathrm{C}[\mathrm{k}$ $+1, \mathrm{n}]$ and the right side vector $\mathrm{b}$ for $\mathrm{n}$ projects.

$$
\begin{gathered}
\mathrm{C} \cdot \mathrm{x}=\mathrm{b} \\
{\left[\begin{array}{ccc}
\mathrm{a}_{11} & \cdots & \mathrm{a}_{1 \mathrm{n}} \\
\vdots & \ddots & \vdots \\
\mathrm{a}_{\mathrm{k} 1} & \cdots & \mathrm{a}_{\mathrm{kn}} \\
\mathrm{c}_{1} & \cdots & \mathrm{c}_{\mathrm{n}}
\end{array}\right]\left[\begin{array}{c}
\mathrm{x}_{1} \\
\vdots \\
\mathrm{x}_{\mathrm{n}}
\end{array}\right] \leq\left[\begin{array}{c}
\mathrm{b}_{1} \\
\vdots \\
\mathrm{b}_{\mathrm{k}} \\
1
\end{array}\right],}
\end{gathered}
$$

Where:

k...number of limitations [-],

n...number of projects [-].

$$
\sum_{i=1}^{n} c_{i}=1 \text {, }
$$

It will created a matrix $X[n, m]$ of all possible combinations of projects where $n$ is the number of projects and $\mathrm{m}$ is the number of all combinations 0 and 1 .

$$
\mathrm{m}=\sum_{\mathrm{i}=0}^{\mathrm{n}}\left(\begin{array}{c}
\mathrm{n} \\
\mathrm{i}
\end{array}\right)=2^{\mathrm{n}}
$$

The elements of the $j$-th column $(j=1, . ., m)$ of the matrix $X$ are obtained by converting the number $(j-1)$ into the binary system (ie by converting the numbers 0 to $\mathrm{m}$ 1).

Than you have to calculate the matrix $\mathrm{E}[\mathrm{k}+1, \mathrm{~m}]$ for all combinations.

$$
\mathrm{E}=\mathrm{C} \cdot \mathrm{X}
$$

Again, we created a source program for this solution in a freely available MAXIMA program for calculation.

- $\quad 17$ th Select the highest weighted combination of satisfying the specified constraints

We are looking for such combination, which would meet requiremnts. The result is listed at the end of the source program as the chosen solution. Where 1 is indicated, the project will be implemented, instead, the project, where 0 is stated, will not be implemented.

\section{Conclusion}

This methodology has been verified in a case study containing real data provided by the engineering company. Verification of case study was carried out as follows. First, projects were evaluated using the ANP method and the DEMATEL method. Subsequently, the allocation of insufficient resource capacities between projects was made. This was solved using a mathematical model containing source limitations and a purpose function occurring in linear programming.

All calculations were made using the MAXIMA and Super Decisions software tools. Part of the methodology are source programs created in Maxima software. One of them can be used to solve any problem with the DEMATEL method. The second is looking for combination of projects, which meets the required source limits.

The novelty of the proposed methodology lies above all in a comprehensive approach to this issue. It follows from practical verification that with correct input data, the methodology is usable at the selection and evaluation of the project portfolio.

\section{References}

[1] ALTUNTAS, S., DERELI, T. A novel approach based on DEMATEL method and patent station analysis for prioritizing a portfolio of investment projects. Expert Systems with Application. 22 September 2014, Volume 42, Issue 3, 1003-1012. ISSN 0957-4174.

[2] ENGWALL, M. No project is an island: Linking projects to history and context. Research Policy. May 2003, Volume 32, Issue 5, 789-808. ISSN 0048-7333.

[3] FIALA, P., A Hybrid Procedura for Network Multi-Criteria Systems. Acta Universitatis Palackianae Olomucensis, Mathematica. 2013, Volume 52, Issue 2, 53-60. ISSN 0231-9721.

[4] MEHREGAN, M. R., RAZAVI, S. M., ANVARI, M. R. A. Identification and Evaluation of Strategic Decisions in Gas Industry Using DEMATEL Method. Iranian Journal of Management Studies. 2012, Volume 5, No. 2. ISSN 2008-7055.

[5] SAATY, T. L. The analytic network process, Iranian Journal of Operations Research [online]. Winter 2008, 1(1) [cit. 3. června 2014] Dostupné http://www.sid.ir/En/VEWSSID/J_pdf/11572008 0101.pdf

[6] VYSLOUŽIlovÁ, D., FIALA, P.: A Methodology for Selecting Portfolios of Projects, In: Perspectives of Business and Entrepreneurship Development, Brno, 28.-29. 5. 2015. FP VUT Brno. 